\title{
A high-throughput cell- and virus-free assay shows reduced neutralization of SARS-CoV-2 variants by COVID- 19 convalescent plasma
}

\author{
Craig Fenwick $^{\ddagger 1}$, Priscilla Turelli ${ }^{\ddagger 2}$, Céline Pellaton ${ }^{1}$, Alex Farina $^{1}$, Jérémy Campos $^{1}$, Charlène Raclot ${ }^{2}$, Florence \\ Pojer $^{2}$, Valeria Cagno ${ }^{3,4}$, Semira Gonseth Nusslé ${ }^{5}$, Valerie D’Acremont ${ }^{5,6}$, Jan Fehr ${ }^{7}$, Milo Puhan ${ }^{7}$, Giuseppe \\ Pantaleo $^{1,8,9 *}$, Didier Trono ${ }^{2 *}$ \\ ${ }^{1}$ Service of Immunology and Allergy, Department of Medicine, Lausanne University Hospital and University of Lausanne, 1011 Lausanne, Switzerland. ${ }^{2}$ School of Life \\ Sciences, Ecole Polytechnique Fédérale de Lausanne, 1015 Lausanne, Switzerland. ${ }^{3}$ Department of Microbiology and Molecular Medicine, University of Geneva, 1211 Geneva, \\ Switzerland. ${ }^{4}$ Institute of Microbiology, Lausanne University Hospital, University of Lausanne, 1011 Lausanne, Switzerland. ${ }^{5}$ Centre for Primary Care and Public Health, \\ University of Lausanne, 1011 Lausanne, Switzerland. ${ }^{6}$ Swiss Tropical and Public Health Institute, University of Basel, 4001 Basel, Switzerland. 7 University of Zurich, \\ Epidemiology, Biostatistics and Prevention Institute, 8001 Zurich, Switzerland. ${ }^{8}$ Swiss Vaccine Research Institute, Lausanne University Hospital and University of Lausanne, \\ 1011 Lausanne, Switzerland. ${ }^{9} \mathrm{VRI}$, Université Paris-Est Créteil, Faculté de Médicine, INSERM U955, 94010 Créteil, France. \\ $\ddagger$ Authors contributing equally \\ *Corresponding author. Email: didier.trono@epfl.ch; giuseppe.pantaleo@chuv.ch
}

The detection of severe acute respiratory syndrome coronavirus 2 (SARS-CoV-2)-specific antibodies in the serum of an individual indicates prior infection or vaccination. However, it provides limited insight into the protective nature of this immune response. Neutralizing antibodies recognizing the viral spike protein are more revealing, yet their measurement traditionally requires virus- and cell-based systems that are costly, time-consuming, inflexible, and potentially biohazardous. Here, we present a cell-free quantitative neutralization assay based on the competitive inhibition of trimeric SARS-CoV-2 spike protein binding to the angiotensin converting enzyme 2 (ACE2) receptor. This high-throughput method matches the performance of the gold standard live virus infection assay, as verified with a panel of 206 seropositive donors with varying degrees of infection severity and virus-specific IgG titers, achieving $96.7 \%$ sensitivity and $100 \%$ specificity. Furthermore, it allows for the parallel assessment of neutralizing activities against multiple SARS-CoV-2 spike protein variants of concern. We used our assay to profile serum samples from 59 patients hospitalized with coronavirus disease 2019 (COVID-19). We found that, although most sera had high activity against the 2019-nCoV parental spike protein and, to a lesser extent, the $\alpha$ (B.1.1.7) variant, only $58 \%$ of serum samples could efficiently neutralize a spike protein derivative containing mutations present in the $\beta$ (B.1.351) variant. Thus, we have developed an assay that can evaluate effective neutralizing antibody responses to SARS-CoV-2 spike protein variants of concern after natural infection and that can be applied to characterize vaccine-induced antibody responses or to assess the potency of monoclonal antibodies.

\section{INTRODUCTION}

The coronavirus 2019 (COVID-19) pandemic caused by severe acute respiratory syndrome coronavirus 2 (SARS-CoV-2) has led to a global crisis with a devastating impact on public health and economies around the world $(1,2)$. The majority of individuals infected with SARS-CoV-2 experience mild to moderate symptoms that do not require hospitalization, but risk factors, including age, ethnicity, gender, or obesity and underlying health issues, including cardiovascular disease, diabetes and chronic respiratory disease, can lead to severe illness (3). COVID-19 has so far resulted in greater than 3.5 million deaths worldwide, and it is estimated that approximately $5-10 \%$ of symptomatic infected individuals will have long term health consequences (4).

The global spread of SARS-CoV-2 led to the rapid development of diagnostic tools, including viral detection tests and serological assays, to assist in the public health management of the pandemic $(5,6)$. Seroprevalence studies generally search for the presence of virus-specific antibodies in the serum of individuals as a marker of previous infection or vaccination. However, these analyses do not determine whether the detected immune response is protective (7). Indeed, only a subset of antibodies mounted against a virus can block its spread. These are called neutralizing antibodies, and in the case of SARS-CoV-2 they most often recognize spike, the viral surface protein responsible for mediating entry through 
binding of the angiotensin converting enzyme 2 (ACE2) receptor $(8,9)$.

The gold standard for measuring abundance of SARSCoV-2-specific neutralizing antibodies relies on infection of ACE2-expressing cells with live virus, monitoring the reduction in the culture of virus-induced cytopathic effects (CPE) or, if a virus modified to encode green fluorescent protein (GFP) or luciferase is used, the expression of these reporters (10). Such neutralization assays are not routinely performed because they are technically demanding, take several days for readout, and require trained professionals working in biosafety level 3 (BSL3) facilities. As an alternative, viral pseudotypes can be utilized, typically lentiviral vector (LV) or vesicular stomatitis virus (VSV) particles coated with the SARS-CoV-2 spike protein to drive their entry into ACE2positive target cells. Although compatible with the less constrained environment of biosafety level 2 laboratories, these assays still require cell culture and take several days (11). Furthermore, neither LV nor VSV pseudotypes fully recapitulate SARS-CoV-2 infectivity, because their virions assemble at the plasma membrane, whereas the coronavirus loads its spike protein in the endoplasmic reticulum-Golgi intermediate compartment (12). As a result, these -pseudotyped virions are difficult to produce as highly infectious particles and are inherently easier to neutralize compared to the authentic SARS-CoV-2 virus, leading to often erratic estimations of the neutralizing activity of biological samples.

Measuring the neutralizing activity of virus-specific antibodies is further complicated by the continuous emergence of SARS-CoV-2 variants. Some of these variants are of particular clinical relevance, such as ones with mutations in and around the receptor binding domain (RBD) of the spike protein, resulting in increased affinity for the ACE2 receptor or reduced recognition by neutralizing antibodies $(13,14)$. For instance, the $\beta$ variant of concern (VOC), also called B.1.351, $501 Y . V 2$ or South African, has been found largely to escape immunity induced by some COVID-19 vaccines, (15) and the closely related $\curlyvee$ VOC, also called P.1, 501Y.V3, B.1.1.28 or Brazilian, to be responsible for large numbers of reinfections in the Manaus region (16).

To address these challenges, we developed a cell-free neutralization assay based on the competitive inhibition of ACE2 binding to spike protein trimer-bearing beads. This method is high-throughput, quantitative, yields results that correlate those obtained with a classical wild-type virus cell-based neutralization assay, and allows the simultaneous evaluation of multiple spike protein variants.

\section{RESULTS}

Development of a cell-free SARS-CoV-2 spike protein
trimer and ACE2-based neutralization assay. SARS-CoV-2 uses ACE2 as its primary receptor, which it recognizes by the RBD of its spike protein (17). This 211 amino acid-long region is also the main target of neutralizing antibodies $(8,18,19)$. We thus hypothesized that an assay capable of providing a quantitative measurement of the inhibition of SARS-CoV-2 spike protein interaction with ACE2 could reveal the neutralizing potential of antibodies found in serum and other biological samples. However, whereas a previously described system based on this assumption relied on the sole use of spike protein RBD monomers (20), we reasoned that having the full spike protein in trimeric higher order structure, as found on the surface of the virion, was more likely to recapitulate the physiological configuration (21). Therefore, we produced spike protein trimers $\left(\mathrm{S}^{3}\right)$ in their native prefusion configuration (22) in Chinese hamster ovary (CHO) cells and coupled these proteins to Luminex beads. We then measured the ability of these $S^{3}$-bearing beads to recruit a recombinant human ACE2 fusion protein tagged with a mouse Fc (ACE2-Fc), which we detected with a fluorescently tagged anti-mouse Fc secondary antibody. A standard protocol was then established (Fig. 1A), where $\mathbf{S}^{3}$-carrying beads were first mixed in a 96 -well plate with limited dilutions of test sera, then ACE2-Fc was added and samples were incubated for 60 min in order to reach equilibrium. Finally, the amount of captured soluble viral receptor was measured with a fluorescently tagged antibody on a Bio-Plex 200 System. The fluorescence for bound ACE2-Fc over the background signal was greater than 100-fold for all beads prepared and used in these studies. Using this procedure, we first verified that serum samples from pre-COVID-19 pandemic healthy donors (n=104, Fig. 1B and C) did not cross-react (2) and interfere with ACE2-Fc binding to $\mathrm{S}^{3}$-coupled beads, whereas serum from post-infected donors induced a dilution-dependent signal reduction (Fig. 1C).

The cell-free SARS-CoV-2 spike protein trimer and ACE2-based assay determined neutralization activity of sera from patients.

We next validated the surrogate neutralization assay with a panel of 206 post-infection serums obtained from individuals, some with a prior history of reverse transcription polymerase chain reaction (RT-PCR)-documented symptomatic infection that did or did not require hospitalization $(n=95)$, and others without known SARS-CoV-2 antecedent but identified as seropositive in a Swiss population serological survey $(\mathrm{n}=111)$, as determined using a previously described Luminexbased spike protein trimer serological assay (table S1) (21). As expected, those with symptomatic disease presented with higher average serum anti-spike protein IgG or IgA abundance (Fig. 2). These 206 serum samples were tested in parallel with the cell-free $\mathrm{S}^{3}$-ACE2 assay and a conventional live CPE assay in Vero cells. The results revealed a high correlation of the neutralizing titers obtained with the two assays $\left(\mathrm{R}^{2}=0.825\right)$ over the greater than 3 log range measured 
amongst the various samples (Fig. 3A). We additionally tested a subset of these serums $(n=74)$ with a LV reporter pseudotype-based neutralization assay, which revealed a weaker correlation with the live virus assay $\left(\mathrm{R}^{2}=0.65, \mathrm{n}=74\right.$; Fig. 3B).

For the $\mathrm{S}^{3}$-ACE2 neutralization assay, a lower limit half maximal inhibitory concentration $\mathrm{IC}_{50}$ serum dilution of 50 was set as the specificity cutoff using $\mathrm{IC}_{50}$ values for the 104 pre-COVID-19 pandemic healthy donor samples (50 cut-off = 12.5 mean $\mathrm{IC}_{50}+4 \times 9.0 \mathrm{SD}$ to minimize detection of false positive samples; Fig. 1B). A serum dilution $\mathrm{IC}_{50}$ of 20 was selected as the cutoff for positivity in the live SARS-CoV-2 virus CPE assay given that this corresponds to $95-99 \%$ viral neutralization as determined for undiluted serum samples by nonlinear regression with 1 and 1.5 Hill slopes values to achieve $\mathrm{IC}_{95}$ and $\mathrm{IC}_{99}$, respectively (fig. S1). (23) Using these criteria, the surrogate neutralization assay achieved $96.7 \%$ (95\% confidence interval (CI) of 96.85-100\%) sensitivity (118 out of 122 ) and $100 \%$ (95\% CI of $95.63-100 \%$ ) specificity (0 out of 84 ) relative to the live virus CPE assay (Table 1).

Illustrating the high-throughput screening capability of the $S^{3}$-ACE2 assay, we estimated that one person could, on average, prepare and analyze eight 96-well plates in a day, generating $\mathrm{IC}_{50}$ values for at least 100 samples in six-point serum dilution response curves. The standard protocol requires less than 2 hours total hand on preparation time, 3 hours of incubation and washing steps, and 20 to $40 \mathrm{~min}$ of instrument analysis per plate, respectively. This throughput could be further increased 6 -fold to greater than 600 samples per day using a single point 1:50 serum dilution in a qualitative assay format for positive or negative detection of serum neutralizing antibodies.

\section{The surrogate neutralization assay can be multiplexed} to evaluate neutralization of SARS-CoV-2 VOCs.

A characteristic of Luminex bead-based assays is the use of analytical optics that allow for the simultaneous evaluation of analytes captured by multiple baits, each coupled to beads of different colors. Beads aspirated from a sample well are passed through a flow cell and are individually scanned with a red $635 \mathrm{~nm}$ laser to identify beads labeled with a spectrally distinct set of dyes and dye concentrations. With this bead ID-based multiplex method, 80 different unique readouts are available using a Luminex 200 instrument. A separate green $532 \mathrm{~nm}$ laser is dedicated to excite the phycoerythrin (PE) fluorophore used in the assay for specific detection of ACE2$\mathrm{Fc}$ binding. The robustness in $\mathrm{IC}_{50}$ curve responses between different labeled beads in the $\mathrm{S}^{3}$-ACE2 assay was verified by demonstrating that four distinct colored beads coupled with different protein concentrations of 2019-nCoV spike protein resulted in different maximum mean fluorescence intensities (MFIs) for ACE2-Fc binding in the absence of serum, but virtually identical $\mathrm{IC}_{50}$ curves for two different serum samples (fig. S2A and B). We thus took advantage of this multiplexing feature to test, in parallel, the neutralization potential of post-infection sera against a large array of SARS-CoV-2 spike protein variants. For this, we produced a set of spike protein derivatives containing specific mutations alone or in combination. We included amino acid changes suspected to contribute to immune escape of some VOCs, such as substitutions at positions K417, E484 and N501 found in the $\alpha, \beta$, and $\gamma$ variants (Table 2) $(15,16,24)$. We then coupled each of the corresponding spike protein trimers to beads of a given color, and placed equal amounts of each of these beads in the wells of a 96 -well plate. To validate the utility of the $\mathrm{S}^{3}$ ACE2 assay in identifying spike protein mutations conferring reduced sensitivity to neutralization, concentration response curves were generated with the REGN10933 and REGN10987 therapeutic antibodies profiled against the $S 477 \mathrm{~N}$, $\mathrm{K} 417 \mathrm{~N} / \mathrm{E} 484 \mathrm{~K} / \mathrm{N} 501 \mathrm{Y}$ and $\triangle 69-70 \mathrm{Y} 453 \mathrm{~F}$ spike protein mutations present in the 20A.EU2 lineage, $\beta$ variant and a SARSCoV-2 variant isolated from a mink, respectively (Fig. 4A). Consistent with published results, REGN10933 displayed a marked loss in potency against spike proteins harboring mutations from either the $\beta$ or mink variants (22- and 34-fold drop in $\mathrm{IC}_{50}$ activity, respectively) $(16,25)$. As previously reported (16), the potency of REGN10987 was not affected by the set of spike protein mutations tested in this setting. We additionally tested MS42, a neutralizing antibody recently identified by our group (26), and found it to exhibit an intermediate neutralizing profile, with reduced activity only against the K417N/E484K/N501Y spike protein. We then performed the neutralization assay on a large series of post-infection sera (representative examples of which are shown in Fig. $4 B$ and C). In an spike protein panel consisting of single amino acid mutations, sera from two donors exhibited high neutralizing antibody titers (greater than 1,000 $\mathrm{IC}_{50}$ ) against the parental 2019-CoV spike protein, as measured in duplicates with beads of two different colors (MFI values for each bead are shown in fig. S2C). Whereas one sample (3506) retained full potency against a series of seven spike proteins with point mutations, the other sample (9504) displayed a greater than two log reduced ability to block the interaction of ACE2 with the E484K spike protein mutant, a result corroborated by an LV pseudotype reporter assay (fig. S3).

An additional panel of $\mathrm{S}^{3}$-coupled beads was manufactured to evaluate mutations present in the 501Y lineage circulating SARS-CoV-2 variants, including the $\alpha$ and $\beta$ or $\gamma$ VOCs (Fig. 4C and D). Sera from a representative donor (sample 1034) exhibited neutralizing antibody concentrations in the higher range of activity (greater than $100 \mathrm{IC}_{50}$ serum dilution) against the 2019-nCov spike protein but only retained moderate blocking activity against most spike protein derivatives with single or multiple mutations (Fig. 4D). Importantly, this serum was almost completely inefficient 
against spike proteins containing the $\mathrm{E} 484 \mathrm{~K}$ mutation found in the $\beta$ and $\gamma$ VOCs (less than $50 \mathrm{IC}_{50}$; light red range). Another serum sample (5537) had a stronger overall neutralization activity but still displayed lower efficacy against spike protein derivatives harboring the $\mathrm{E} 484 \mathrm{~K}$ mutation or against the $\alpha$ variant $\left(\mathrm{IC}_{50}\right.$ serum dilutions between 30 and 76 ).

To illustrate the broad screening capability of the $\mathrm{S}^{3}$-ACE2 assay, neutralizing antibody titers against the $2019-\mathrm{CoV}$ and three spike protein variants were measured in sera from 59 patients with COVID-19 who were hospitalized with $(\mathrm{n}=31)$ or without ( $n=28)$ need for intensive care unit (ICU) admission (Fig. 5). The majority of patients from both subgroups, all of whom had been infected prior to November 2020, exhibited strong neutralizing activity when profiled against the 2019nCoV spike protein, with $93 \%$ of non-ICU and $100 \%$ of ICU patients having greater than 50 serum dilution $\mathrm{IC}_{50}$ cut-offs. Based on our cross-validation studies, this cut-off value corresponds to antibody concentrations in undiluted serum samples that would be sufficient to achieve near complete neutralization in the live virus CPE assay (Fig. S1) However, they were less efficient at blocking ACE2 interaction with the spike protein found in the $\alpha$ variant or derivatives containing the $\mathrm{S} 477 \mathrm{~N}$ substitution or the $\mathrm{K} 417 \mathrm{~N} / \mathrm{E} 484 \mathrm{~K} / \mathrm{N} 501 \mathrm{Y}$ triple RBD mutation encountered in the $\beta$ variant. Both groups notably exhibited a marked reduction in median $\mathrm{IC}_{50}$ against this latter allele $(\mathrm{P}<0.0001)$, with only $58 \%$ ( $43 \%$ of non-ICU and $71 \%$ of ICU patients) displaying antibody concentrations above the cut-off at an $\mathrm{IC}_{50}$ of 50 . ICU patients exhibited a modestly higher median antibody activity for each of the spike proteins tested when compared to the median antibody activity for non-ICU patients ( $\mathrm{P}=0.0127$ to 0.091$)$. This is consistent with a model whereby more severe and prolonged infections lead to stronger humoral immune responses.

\section{DISCUSSION}

Determining the degree of immune protection conferred by prior SARS-CoV-2 infection, vaccination, or the prophylactic administration of monoclonal antibodies is of high importance for informing individuals about their susceptibility to the virus, for adapting prophylactic measures to the evolving viral strains circulating in the population and, ultimately, for controlling the COVID-19 pandemic. Although $\mathrm{T}$ cellbased responses may contribute to this immunity (27), neutralizing antibodies likely play a primary role in this process as they do for other acute viral infections and represent the best available surrogate marker of protection $(9,28)$. However, serum abundance of SARS-CoV-2 neutralizing antibodies are so far only rarely measured owing to technical difficulties and biosafety requirements, which limits their use in routine procedure as well as any substantial scale-up.

Addressing this shortcoming, we report here the development of a cell-free assay that allows for the quantitative and high-throughput evaluation of the neutralizing activity of biological samples, such as serum, against multiple SARSCoV-2 variants in a single procedure taking less than four hours in a standard diagnostic laboratory. The $\mathrm{S}^{3}$-ACE2 assay relies on the fact that most neutralizing antibodies interfere with the binding of the viral spike protein with its ACE2 receptor. Although neutralizing antibodies have been identified that recognize spike protein outside of the RBD (9) and do not directly inhibit ACE2 binding, these are rare, as confirmed by the very high degree of correlation between our surrogate assay using the trimeric spike and the live virus cell-based reference counterpart used, irrespective of neutralizing activity (8). Our assay provides quantitative measures of serum neutralizing antibody activity and is further characterized by a high degree of sensitivity (greater than 96\%) and specificity (100\%). This performance of the $S^{3}$-ACE2 assay is comparable to the sensitivity and specificity recently reported by Tan et al. in a SARS-CoV-2 RBD-ACE2 enzyme linked immunosorbent assay (ELISA)-based protein-protein interaction assay (20). However, their use of serum samples from COVID-19 patients, as opposed to seropositive donors with lower anti-SARS-CoV-2 antibodies used in our study may represent a less stringent assessment of their assay performance. An additional advantage of the $\mathrm{S}^{3}$-ACE2 neutralization assay is its ability to evaluate multiple spike variants in parallel using as little at $15 \mu \mathrm{l}$ of serum, allowing the identification of an individual's susceptibility to circulating and emerging SARS-CoV-2 viruses, whether after infection or vaccination. This was demonstrated with serum samples from 59 patients with COVID-19 infected prior to the widespread emergence of VOCs. Importantly, only $43 \%$ of non-ICU hospitalized patients had neutralizing antibody activity greater than 50 serum dilution $\mathrm{IC}_{50}$ against the spike protein with the $\mathrm{K} 417 \mathrm{~N} / \mathrm{E} 484 \mathrm{~K} / \mathrm{N} 501 \mathrm{Y}$ mutation found in the $\beta$ variant, suggesting that many who have been previously infected with the parental strain of SARS-CoV-2 are not fully protected against this variant. The $\gamma$ variant originally identified in Brazil has a similar mutation profile in the RBD, and some of these nonICU patients would be predicted to be susceptible to infection by this SARS-CoV-2 variant. Individuals whose infection had required an ICU stay generally displayed higher neutralizing antibody activity against all tested spike protein variants, although they too were less effective against the $\beta-\gamma$ triple mutant.

The multiplexing of the $\mathrm{S}^{3}$-ACE2 neutralization assay could be increased to greater than 40 different spike proteins to evaluate additional VOCs. It advantageously compares with viral pseudotypes-based systems, where each spike protein mutant requires production of a new batch of virions that have to be tested in separate assays, with their infectivity potentially affected by the mutations and neutralization titers influenced by the abundance of ACE2 on the surface of target cells $(29,30)$. As anti-SARS-CoV-2 immunity increases 
in the world population due to the combined influence of ongoing infections and more widespread vaccination, selective pressures will increasingly be exerted on the virus, favoring the emergence of escape mutants. The detection of these escapees should be as fast as possible for the swift adaptation of prophylactic measures including vaccines. Although the infection of previously infected or vaccinated individuals will remain the strongest evidence of gaps in collective immunity, a surveillance system based on the routine sequencing of viral isolates and the immediate testing of the susceptibility of their spike protein to neutralization would constitute a dynamic and anticipatory approach. The $\mathrm{S}^{3}$-ACE2 assay, because of its ease of use, would facilitate such surveillance strategy and longitudinal studies aimed at further evaluating the relative importance of neutralizing antibodies, compared with other types of humoral or $\mathrm{T}$ cell-based responses, in conferring protective immunity against SARS-CoV-2 infection and reinfection. Furthermore, the $\mathrm{S}^{3}$-ACE2 assay could also be used for the high-throughput screening of candidate monoclonal antibodies and other prophylactic or therapeutic approaches aimed at blocking the interaction between SARSCoV-2 and ACE2, and it could be adapted to other viruses for which the molecular mediators of viral entry are properly characterized.

Our study has several limitations. First, it was not designed to seek a correlation between neutralization activity and protection against re-infection. Second, it did not include individuals that had been vaccinated, precluding a comparison between post-infection and post-vaccination neutralizing activities. Third, it did not involve children, whose immune responses may differ from those of adults, and did not comprise a long-term longitudinal follow up of tested individuals. However, the ease-of-use of the $\mathrm{S}^{3}$-ACE2 assay should allow one to address these points through future studies.

Therefore, the hereby described method stands to have an important impact in both clinical and public health settings. In this regard, immunity passports are at the forefront of current public and political discussions as possible gateways to a return to more normal social and international exchanges as the world emerges from the COVID-19 pandemic (31). They are generally thought of essentially as vaccination certificates, a concept that suffers from major shortcomings. First, such certificates might unduly exclude people that have not yet been vaccinated but endowed with strong antiviral immunity triggered by natural infection. Second, they would not be delivered to individuals that do not respond to vaccination such as those with primary or acquired immunodeficiency, including patients with cancer, transplant recipients, or patients with systemic inflammatory diseases receiving immunosuppressive treatments. These individuals could, however, be protected by passive immunization through the administration of human monoclonal antibodies, the activity of which could be quantified in their serum (32-34). Third, having been vaccinated is not a guarantee of induction of optimal immunity and protection, as found every year with the flu vaccine, and the duration of vaccine-induced SARS-CoV-2 immunity is as yet unknown. A system based on the documentation of a validated surrogate marker of protective immunity against major circulating SARS-CoV-2 strains, such as neutralization indicated by the $\mathrm{S}^{3}$-ACE2 assay described here, should be considered to overcome these limitations.

\section{MATERIALS AND METHODS}

\section{Study Design}

The goal of this study was to validate a high-throughput, cell free surrogate assay of SARS-CoV-2 neutralizing activity, and use it to assess this parameter in individuals having recovered from COVID-19 episodes of various degrees of severity. No prior sample size calculation was performed but serum samples were selected at random from ongoing cohort studies (table S1) in order to test serums with a low to high range of anti-spike protein IgG and IgA antibody concentrations. Neutralization assays were performed blindly, without prior knowledge of the clinical data linked to serum samples.

\section{Seropositive donor population}

Cross-validation studies were performed on serum samples identified from the seroprevalence study of the Vaud Canton in Switzerland (SerocoViD) performed by the Centre for Primary Care and Public Health, University of Lausanne (Unisanté), from the Swiss Population based seroprevalence study performed by Coronas Immunitas and from the with hospitalized donor ImmunoCov study performed by the Immunology and Allergy Service, Lausanne University Hospital. The panel of 206 SARS-CoV-2 seropositive samples consisted of 31 patients hospitalized with COVID-19 and 64 RT-PCR positive non-hospitalized donors for a total of 95 RT-PCR positive donors and 111 seropositive donors identified through contact with RT-PCR positive donors, volunteers, and asymptomatic or pausisymptomatic donors selected at random from the general population (table S1). For the large scale analysis of variants-specific neutralization activity (Fig. 5), serum samples from 59 COVID-19 patients hospitalized with $(n=31)$ or without $(n=28)$ need for stay in the ICU were selected from donors participating in the ImmunoCov study and SerocoVID studies. The non-ICU COVID-19 patients had a mean age of 57.9 ranging from 30 to 92 years old and were $25 \%$ female. The ICU patients has a mean age of 63.0 ranging from 49 to 89 years old and were $26 \%$ female. The study design and use of sera samples were approved by the Institutional Review Board of the Lausanne University Hospital. The 'Commission d'éthique du Canton de Vaud' (CER-VD) stated that authorization and informed consent was not required. 


\section{Pre-COVID-19 pandemic donor population}

Negative control serum samples from 104 adult healthy donors with ages ranging for 18 to 81 years of age were collected prior to November 2019 as part of the Swiss Immune Setpoint study sponsored by the Swiss Vaccine Research Institute. The study design and use of sera samples were approved by the Institutional Review Board of the Lausanne University Hospital. The 'Commission d'éthique du Canton de Vaud' (CER-VD) stated that authorization and informed consent was not required.

\section{Production of SARS-CoV-2 spike proteins}

The spike protein trimer was designed to mimic the native trimeric conformation of the protein in vivo. The expression vector was kindly provided by Jason McLellan, University of Texas, Austin. It encoded the prefusion ectodomain of the original spike protein with a C-terminal T4 foldon fusion domain to stabilize the trimer complex along with C-terminal $8 \mathrm{x}$ His and 2x Strep tags for affinity purification. The trimeric spike protein was transiently expressed in suspensionadapted ExpiCHO cells (Thermo Fisher Scientific) in ProCHO5 medium (Lonza) at $5 \times 10^{6}$ cells/mL using PEI MAX (Polysciences) for DNA delivery. At 1 hour post-transfection, dimethyl sulfoxide (DMSO; AppliChem) was added to $2 \%$ (v/v). Following a 7-day incubation with agitation at $31^{\circ} \mathrm{C}$ and $4.5 \% \mathrm{CO}_{2}$, the cell culture medium was harvested and clarified using a $0.22 \mu \mathrm{m}$ filter. The conditioned medium was loaded onto Streptactin (IBA) and StrepTrap HP (Cytiva) columns in tandem, washed with phosphate-buffered saline (PBS), and eluted with $10 \mathrm{mM}$ desthiobiotin in PBS. The purity of spike protein trimers was determined to be $>99 \%$ pure by SDS-PAGE analysis. Generation of spike protein expression vectors encoding the mutations D614G, D614G plus M153T, N439K, S477N, S477R, E484K, S459Y, N501T, N501Y, $\mathrm{K} 417 \mathrm{~N}, \triangle 60-70, \mathrm{P} 681 \mathrm{H}, \mathrm{Y} 453 \mathrm{~F}$ or combinations thereof were generated by InFusion-mediated site directed mutagenesis using primers listed in table S2. The $\alpha$ variant clone was generated by gene synthesis (Twist Biosciences). Spike proteins for all mutants were produced and purified in an identical manner to the 2019-Cov strain spike protein.

\section{Coupling of Luminex beads with SARS-CoV-2 spike pro- tein}

Luminex beads used for the serological binding assays were prepared by covalent coupling of SARS-CoV-2 proteins with MagPlex beads according to the manufacturer's protocol with a Bio-Plex Amine Coupling Kit (Bio-Rad). Briefly, $1 \mathrm{ml}$ of MagPlex-C Microspheres (Luminex) were washed with wash buffer and then resuspended in activation buffer containing a freshly prepared solution of 1-ethyl-3-(3-dimethylaminopropyl) carbodiimide (EDC) and N-hydroxysulfosuccinimide (SNHS), (Thermo Fisher Scientific). Activated beads were washed in PBS followed by the addition of $50 \mu \mathrm{g}$ of protein antigen. The coupling reaction was performed at $4^{\circ} \mathrm{C}$ overnight with bead agitation using a Hula-Mixer (Thermo Fisher Scientific). Beads were then washed with PBS, resuspended in blocking buffer (Bio-Rad) then incubated for 30 min with agitation at room temperature. Following a final PBS washing step, beads were resuspended in $1.5 \mathrm{ml}$ of storage buffer (Bio-Rad) and kept protected from light in an opaque tube at $4^{\circ} \mathrm{C}$. Each of the SARS-CoV-2 proteins was coupled with different colored MagPlex beads so that tests could be performed with a single protein bead per well or in a multiplexed Luminex serological binding assay.

\section{Cell-free spike protein-ACE2 surrogate neutralization assay}

Spike protein-coupled beads were diluted 1:100 in PBS with $50 \mu \mathrm{l}$ added to each well of a Bio-Plex Pro 96-well Flat Bottom Plates (Bio-Rad). Following bead washing with PBS on a magnetic plate washer (MAG2x program), $80 \mu \mathrm{l}$ of individual serum samples at different dilutions (1:10, 1:30, 1:90, 1:300, 1:2700 and 1:8100) in PBS were added to the plate wells. Control wells were included on each 96 -well plate that included beads alone, matching serum dilutions of a control pool of pre-COVID-19 pandemic healthy human sera (BioWest human serum $\mathrm{AB}$ males; VWR) and a positive control commercial anti-spike blocking antibody (SAD-S35 from ACRO Biosciences) or recombinant produced REGN10933 neutralizing antibody (Regeneron). Plates were agitated on a plate shaker for $60 \mathrm{~min}$, then the ACE2 mouse Fc fusion protein (Creative Biomart or produced by École polytechnique fédérale de Lausanne (EPFL) Protein Production and Structure Core Facility) was then added to each well at a final concentration of $1 \mu \mathrm{g} / \mathrm{ml}$ and agitated for a further $60 \mathrm{~min}$. Beads were then washed on the magnetic plate washer and antimouse IgG-PE secondary antibody (OneLambda, Thermo Fisher Scientific) was added at a 1:100 dilution with $50 \mu \mathrm{l}$ per well. Plates were agitated for $45 \mathrm{~min}$, washed, the beads resuspended in $80 \mu \mathrm{l}$ of reading buffer then read directly on a Bio-Plex 200 plate reader (Bio-Rad). REGN10933 used in this study was a generous gift from Berend-Jan Bosch (Utrecht University). In the validation of beads coupled with 2019$\mathrm{nCoV}$ spike protein or mutants thereof, the mean fluorescence intensity of ACE2-Fc binding and detection with antimouse IgG-PE secondary antibody gave $\pm 50 \%$ signal intensity relative to the reference $2019-\mathrm{nCoV}$ spike protein beads. MFI for each of the beads alone without serum or antibodies were averaged and used as the $100 \%$ binding signal for the ACE2 receptor to the bead coupled spike trimer. MFI from the well containing the high concentration $(>1 \mu \mathrm{g} / \mathrm{ml})$ of commercial anti-spike blocking antibody was used as the maximum inhibition signal. The percent blocking of the spike protein trimer-ACE2 interaction was calculated using the formula: \% Inhibition $=(1-([M F I$ Test dilution - MFI Max inhibition] / [MFI Max binding - MFI Max inhibition] $\times$ 100). Serum dilution response inhibition curves were generated 
with GraphPad Prism 8.3.0 using NonLinear four parameter curve fitting analysis of the log(agonist) versus response. Sensitivity, specificity, and correlations between the assays were calculated with Microsoft Excel and GraphPad Prism 8.3.0.

\section{SARS-CoV-2 live virus cell based cytopathic effect neu- tralization assay}

All biosafety level 3 procedures were approved by EcoGen at the Swiss Federal Office of Public Health. The day before infection, VeroE6 cells were seeded in 96-well plates at a density of $1.25 \times 10^{4}$ cells per well. Heat inactivated sera from patients were diluted 1:10 in Dulbecco's modified Eagle's medium (DMEM) plus $2 \%$ fetal bovine serum (FBS) in a separate 96-well plate. Four-fold dilutions were then prepared in DMEM $+2 \%$ FBS in a final volume of $60 \mu \mathrm{l}$. SARS-CoV-2 (hCoV-19/Switzerland/GE9586) viral stock $\left(2.4 \times 10^{6} / \mathrm{ml}\right.$ as titrated on VeroE6 cells) diluted 1:100 in DMEM plus 2\% FCS was added to the diluted sera at a 1:1 volume/volume ratio. The virus-serum mixture was incubated at $37^{\circ} \mathrm{C}$ for 1 hour then $100 \mu \mathrm{l}$ of the mixture was subsequently added to the VeroE6 cells in duplicate. After 48 hours of incubation at $37^{\circ} \mathrm{C}$, cells were washed once with PBS and fixed with $4 \%$ formaldehyde solution for $30 \mathrm{~min}$ at room temperature. Cells were washed once with PBS and plates were put at $70^{\circ} \mathrm{C}$ for 15 min for a second inactivation. Staining was performed outside the biosafety level 3 laboratory with $50 \mu$ l of $0.1 \%$ crystal violet solution for $20 \mathrm{~min}$ at room temperature. Wells were washed three times with water and plates were dried, scanned, and analyzed for the density of live violet stained cells using ImageJ software (National Institutes of Health). For each 96-well plate, at least four wells were treated with a negative pool of sera from pre-pandemic healthy donors and four wells with virus only and used as negative and positive controls, respectively. The percent inhibition of cytopathic effect of the virus was calculated using the formula: \% Inhibition $=$ (1- ([cell density Test dilution - cell density Max inhibition] / [cell density virus treatment- cell density Max inhibition] $\times 100$. Serum dilution response inhibition curves were generated with GraphPad Prism 8.3.0 using NonLinear four parameter curve fitting analysis of the $\log$ (agonist) versus response. Sensitivity, specificity, and correlations between the assays were calculated with Microsoft Excel and GraphPad Prism 8.3.0. Neutralization $\mathrm{IC}_{50}$ values were calculated as described above for the cell free neutralization assay.

\section{Spike-pseudotyped lentivectors production and neu- tralization assays}

HDM-IDTSpike-fixK plasmid (a kind gift from J.D. Bloom, Fred Hutchinson Cancer Research Center) encoding for the Wuhan-Hu-1 SARS-Cov2 Spike was modified using QuickChange mutagenesis to generate the D614G mutant and D614G/S477N or D614G/E484K double mutants. Primers used are listed in table S2 Spike-pseudotyped lentivectors were generated by co-transfecting HDM-IDTSpike-fixK,
pHAGE2-CMV-Luc-ZSgreen, Hgpm2, REV1b and Tat1b (a kind gift from J.D. Bloom, Fred Hutchinson Cancer Research Center) plasmids into $293 \mathrm{~T}$ cells for 24 hours with the following ratio: 3:9:2:2:2 (18 $\mu \mathrm{g}$ per $56.7 \mathrm{~cm}^{2}$ plate) using Fugene transfection reagent (Promega). The following day, cells were transferred in EpiSerf medium, and cell supernatants were collected after 8 hours and 16 hours. Harvested supernatants were pooled, clarified by low-speed centrifugation, filtered to remove cell debris and aliquoted. Lentivector stocks were titrated and normalized for human immunodeficiency virus antigen p24 content by ELISA (Zeptometrix).

In the pseudoviral neutralization assay, 293T cells stably expressing the ACE2 receptor were suspended in DMEM medium with $10 \%$ FBS and seeded at $1.0 \times 10^{4}$ cells per well into 96 -well plates. After 5 hours in cell culture at $37^{\circ} \mathrm{C}$, three-fold dilutions of serum samples were prepared and pre-incubated with the same amount of each pseudovirus in a final volume of $100 \mu \mathrm{l}$ in DMEM plus 10\% FBS. Following a further 1 hour incubation at $37^{\circ} \mathrm{C}$, the pseudovirus and serum mixtures were added to the 293T ACE2 cells. After 48 hours of incubation at $37^{\circ} \mathrm{C}$, a luciferase assay was performed to monitor pseudoviral infection, using the ONE-Step Luciferase assay system as recommended by the manufacturer (BPS Bioscience). Viral neutralization resulted in the reduction of the relative light units detected. Neutralization $\mathrm{IC}_{50}$ values were calculated as described above.

\section{Statistical Analysis}

The threshold for positivity in the Spike - ACE2 surrogate neutralization assay was established using the mean $\mathrm{IC}_{50}$ value for 104 pre-COVID-19 helathy donor serum samples and adding a multiple of four-fold the standard deviation for the donor population. Statistical differences between seropositive asymptomatic and symptomatic RT-PCR donors for anti-spike IgG and IgA antibody abundances were calculated using a Mann-Whitney test with GraphPad Prism 8.3.0. Cross-validation $\mathrm{R}^{2}$ correlations between SARS-CoV-2 viral CPE neutralization assay and either the Spike protein trimerACE2 surrogate neutralization assay or the pseudoviral SARS-CoV-2 Spike neutralization assay were calculated using Microsoft Excel. In the statistical analysis of the inter-group differences of ICU vsersus non-ICU hospitalized patients for each Spike variant (2019-nCoV, S477N mutant, $\alpha$ variant, $\mathrm{K} 417 \mathrm{~N} / \mathrm{E} 484 \mathrm{~K} / \mathrm{N} 501 \mathrm{Y}$ mutant), serum dilution $\mathrm{IC}_{50}$ values were $\log _{10}$ tranformed to normalize data distribution followed by a two-way analysis of variance (ANOVA). Resulting p-values were corrected for multiple comparisons by controlling the false discovery rate using the two-stage step-up method of Benjamini, Krieger, and Yekutieli. Significant differences were considered to have corrected p-values $<0.1$ and analyses were performed with GraphPad Prism 8.3.0. 


\section{SUPPLEMENTARY MATERIALS}

stm.sciencemag.org/cgi/content/full/scitranslmed.abi8452/DC1

Figs. S1 to S3

Tables S1 and S2

Data file S1

\section{REFERENCES AND NOTES}

1. E. M. Abrams, S. J. Szefler, COVID-19 and the impact of social determinants of health. Lancet Respir. Med. 8, 659-661 (2020). doi:10.1016/S22132600(20)30234-4 Medline

2. P. Zhou, X. L. Yang, X. G. Wang, B. Hu, L. Zhang, W. Zhang, H. R. Si, Y. Zhu, B. Li, C. L. Huang, H. D. Chen, J. Chen, Y. Luo, H. Guo, R. D. Jiang, M. Q. Liu, Y. Chen, X. R. Shen, X. Wang, X. S. Zheng, K. Zhao, Q. J. Chen, F. Deng, L. L. Liu, B. Yan, F. X. Zhan, Y. Y. Wang, G. F. Xiao, Z. L. Shi, A pneumonia outbreak associated with a new coronavirus of probable bat origin. Nature 579, 270-273 (2020). doi:10.1038/s41586-020-2012-7 Medline

3. F. Zhou, T. Yu, R. Du, G. Fan, Y. Liu, Z. Liu, J. Xiang, Y. Wang, B. Song, X. Gu, L. Guan, Y. Wei, H. Li, X. Wu, J. Xu, S. Tu, Y. Zhang, H. Chen, B. Cao, Clinical course and risk factors for mortality of adult inpatients with COVID-19 in Wuhan, China: A retrospective cohort study. Lancet 395, 1054-1062 (2020). doi:10.1016/S01406736(20)30566-3 Medline

4. C. H. Sudre, B. Murray, T. Varsavsky, M. S. Graham, R. S. Penfold, R. C. Bowyer, J. C. Pujol, K. Klaser, M. Antonelli, L. S. Canas, E. Molteni, M. Modat, M. Jorge Cardoso, A. May, S. Ganesh, R. Davies, L. H. Nguyen, D. A. Drew, C. M. Astley, A. D. Joshi, J. Merino, N. Tsereteli, T. Fall, M. F. Gomez, E. L. Duncan, C. Menni, F. M. K. Williams, P. W. Franks, A. T. Chan, J. Wolf, S. Ourselin, T. Spector, C. J. Steves, Attributes and predictors of long COVID. Nat. Med. 27, 626-631 (2021). doi:10.1038/s41591-021-01292-y Medline

5. A. Petherick, Developing antibody tests for SARS-CoV-2. Lancet 395, 1101-1102 (2020). doi:10.1016/S0140-6736(20)30788-1 Medline

6. C. H. GeurtsvanKessel, N. M. A. Okba, Z. Igloi, S. Bogers, C. W. E. Embregts, B. M. Laksono, L. Leiiten, C. Rokx, B. Rijnders, J. Rahamat-Langendoen, J. P. C. van den Akker, J. J. A. van Kampen, A. A. van der Eijk, R. S. van Binnendijk, B. Haagmans, M. Koopmans, An evaluation of COVID-19 serological assays informs future diagnostics and exposure assessment. Nat. Commun. 11, 3436 (2020). doi:10.1038/s41467-020-17317-y Medline

7. N. M. A. Okba, M. A. Müller, W. Li, C. Wang, C. H. GeurtsvanKessel, V. M. Corman, M. M. Lamers, R. S. Sikkema, E. de Bruin, F. D. Chandler, Y. Yazdanpanah, Q. Le Hingrat, D. Descamps, N. Houhou-Fidouh, C. B. E. M. Reusken, B.-J. Bosch, C. Drosten, M. P. G. Koopmans, B. L. Haagmans, Severe Acute Respiratory Syndrome Coronavirus 2-Specific Antibody Responses in Coronavirus Disease Patients. Emerg. Infect. Dis. 26, 1478-1488 (2020). doi:10.3201/eid2607.200841 Medline

8. L. Piccoli, Y. J. Park, M. A. Tortorici, N. Czudnochowski, A. C. Walls, M. Beltramello, C. Silacci-Fregni, D. Pinto, L. E. Rosen, J. E. Bowen, O. J. Acton, S. Jaconi, B. Guarino, A. Minola, F. Zatta, N. Sprugasci, J. Bassi, A. Peter, A. De Marco, J. C. Nix, F. Mele, S. Jovic, B. F. Rodriguez, S. V. Gupta, F. Jin, G. Piumatti, G. Lo Presti, A. F. Pellanda, M. Biggiogero, M. Tarkowski, M. S. Pizzuto, E. Cameroni, C. HavenarDaughton, M. Smithey, D. Hong, V. Lepori, E. Albanese, A. Ceschi, E. Bernasconi, L. Elzi, P. Ferrari, C. Garzoni, A. Riva, G. Snell, F. Sallusto, K. Fink, H. W. Virgin, A. Lanzavecchia, D. Corti, D. Veesler, Mapping Neutralizing and Immunodominant Sites on the SARS-CoV-2 Spike Receptor-Binding Domain by Structure-Guided High-Resolution Serology. Cell 183, 1024-1042.e21 (2020). doi:10.1016/i.cell.2020.09.037 Medline

9. C. O. Barnes, A. P. West Jr., K. E. Huey-Tubman, M. A. G. Hoffmann, N. G. Sharaf, P. R. Hoffman, N. Koranda, H. B. Gristick, C. Gaebler, F. Muecksch, J. C. C. Lorenzi, S. Finkin, T. Hägglöf, A. Hurley, K. G. Millard, Y. Weisblum, F. Schmidt, T. Hatziioannou, P. D. Bieniasz, M. Caskey, D. F. Robbiani, M. C. Nussenzweig, P. J. Bjorkman, Structures of Human Antibodies Bound to SARS-CoV-2 Spike Reveal Common Epitopes and Recurrent Features of Antibodies. Cell 182, 828-842.e16 (2020). doi:10.1016/i.cell.2020.06.025 Medline

10. J. B. Case, P. W. Rothlauf, R. E. Chen, N. M. Kafai, J. M. Fox, B. K. Smith, S. Shrihari, B. T. McCune, I. B. Harvey, S. P. Keeler, L. M. Bloyet, H. Zhao, M. Ma, L. J. Adams, E. S. Winkler, M. J. Holtzman, D. H. Fremont, S. P. J. Whelan, M. S. Diamond, Replication-Competent Vesicular Stomatitis Virus Vaccine Vector Protects against SARS-CoV-2-Mediated Pathogenesis in Mice. Cell Host Microbe 28, 465- 474.e4 (2020). doi:10.1016/i.chom.2020.07.018 Medline

11. J. Nie, Q. Li, J. Wu, C. Zhao, H. Hao, H. Liu, L. Zhang, L. Nie, H. Qin, M. Wang, Q. Lu, X. Li, Q. Sun, J. Liu, C. Fan, W. Huang, M. Xu, Y. Wang, Establishment and validation of a pseudovirus neutralization assay for SARS-CoV-2. Emerg. Microbes Infect. 9, 680-686 (2020). doi:10.1080/22221751.2020.1743767 Medline

12. S. Klein, M. Cortese, S. L. Winter, M. Wachsmuth-Melm, C. J. Neufeldt, B. Cerikan, M. L. Stanifer, S. Boulant, R. Bartenschlager, P. Chlanda, SARS-CoV-2 structure and replication characterized by in situ cryo-electron tomography. Nat. Commun. 11, 5885 (2020). doi:10.1038/s41467-020-19619-7 Medline

13. S. Ozono, Y. Zhang, H. Ode, K. Sano, T. S. Tan, K. Imai, K. Miyoshi, S. Kishigami, T. Ueno, Y. Iwatani, T. Suzuki, K. Tokunaga, SARS-CoV-2 D614G spike mutation increases entry efficiency with enhanced ACE2-binding affinity. Nat. Commun. 12 , 848 (2021). doi:10.1038/s41467-021-21118-2 Medline

14. B. Korber, W. M. Fischer, S. Gnanakaran, H. Yoon, J. Theiler, W. Abfalterer, N. Hengartner, E. E. Giorgi, T. Bhattacharya, B. Foley, K. M. Hastie, M. D. Parker, D. G. Partridge, C. M. Evans, T. M. Freeman, T. I. de Silva, C. McDanal, L. G. Perez, H. Tang, A. Moon-Walker, S. P. Whelan, C. C. LaBranche, E. O. Saphire, D. C. Montefiori; Sheffield COVID-19 Genomics Group, Tracking Changes in SARS-CoV2 Spike: Evidence that D614G Increases Infectivity of the COVID-19 Virus. Cell 182, 812-827.e19 (2020). doi:10.1016/i.cell.2020.06.043 Medline

15. D. Zhou, W. Dejnirattisai, P. Supasa, C. Liu, A. J. Mentzer, H. M. Ginn, Y. Zhao, H. M. E. Duyvesteyn, A. Tuekprakhon, R. Nutalai, B. Wang, G. C. Paesen, C. LopezCamacho, J. Slon-Campos, B. Hallis, N. Coombes, K. Bewley, S. Charlton, T. S. Walter, D. Skelly, S. F. Lumley, C. Dold, R. Levin, T. Dong, A. J. Pollard, J. C. Knight, D. Crook, T. Lambe, E. Clutterbuck, S. Bibi, A. Flaxman, M. Bittaye, S. BelijRammerstorfer, S. Gilbert, W. James, M. W. Carroll, P. Klenerman, E. Barnes, S. J. Dunachie, E. E. Fry, J. Mongkolsapaya, J. Ren, D. I. Stuart, G. R. Screaton, Evidence of escape of SARS-CoV-2 variant B.1.351 from natural and vaccine-induced sera. Cell 184, 2348-2361.e6 (2021). doi:10.1016/i.cell.2021.02.037 Medline

16. P. Wang, M. S. Nair, L. Liu, S. Iketani, Y. Luo, Y. Guo, M. Wang, J. Yu, B. Zhang, P. D. Kwong, B. S. Graham, J. R. Mascola, J. Y. Chang, M. T. Yin, M. Sobieszczyk, C. A Kyratsous, L. Shapiro, Z. Sheng, Y. Huang, D. D. Ho, Antibody resistance of SARSCoV-2 variants B.1.351 and B.1.1.7. Nature 593, 130-135 (2021). doi:10.1038/s41586-021-03398-2 Medline

17. M. Hoffmann, H. Kleine-Weber, S. Schroeder, N. Krüger, T. Herrler, S. Erichsen, T. S. Schiergens, G. Herrler, N. H. Wu, A. Nitsche, M. A. Müller, C. Drosten, S Pöhlmann, SARS-CoV-2 Cell Entry Depends on ACE2 and TMPRSS2 and Is Blocked by a Clinically Proven Protease Inhibitor. Cell 181, 271-280.e8 (2020). doi:10.1016/i.cell.2020.02.052 Medline

18. X. Tian, C. Li, A. Huang, S. Xia, S. Lu, Z. Shi, L. Lu, S. Jiang, Z. Yang, Y. Wu, T. Ying, Potent binding of 2019 novel coronavirus spike protein by a SARS coronavirusspecific human monoclonal antibody. Emerg. Microbes Infect. 9, 382-385 (2020). doi:10.1080/22221751.2020.1729069 Medline

19. A. C. Walls, Y. J. Park, M. A. Tortorici, A. Wall, A. T. McGuire, D. Veesler, Structure, Function, and Antigenicity of the SARS-CoV-2 Spike Glycoprotein. Cell 183, 1735 (2020). doi:10.1016/i.cell.2020.11.032 Medline

20. C. W. Tan, W. N. Chia, X. Qin, P. Liu, M. I. Chen, C. Tiu, Z. Hu, V. C. Chen, B. E. Young, W. R. Sia, Y. J. Tan, R. Foo, Y. Yi, D. C. Lye, D. E. Anderson, L. F. Wang, A SARSCoV-2 surrogate virus neutralization test based on antibody-mediated blockage of ACE2-spike protein-protein interaction. Nat. Biotechnol. 38, 1073-1078 (2020). doi:10.1038/s41587-020-0631-z Medline

21. C. Fenwick, A. Croxatto, A. T. Coste, F. Pojer, C. André, C. Pellaton, A. Farina, J. Campos, D. Hacker, K. Lau, B. J. Bosch, S. Gonseth Nussle, M. Bochud, V. D'Acremont, D. Trono, G. Greub, G. Pantaleo, Changes in SARS-CoV-2 Spike versus Nucleoprotein Antibody Responses Impact the Estimates of Infections in Population-Based Seroprevalence Studies. J. Virol. 95, ‥ (2021). doi:10.1128/JVI.01828-20 Medline

22. D. Wrapp, N. Wang, K. S. Corbett, J. A. Goldsmith, C. L. Hsieh, O. Abiona, B. S. Graham, J. S. McLellan, Cryo-EM structure of the 2019-nCoV spike in the prefusion conformation. Science 367, 1260-1263 (2020). doi:10.1126/science.abb2507 Medline

23. C. M. Trombetta, E. Montomoli, Influenza immunology evaluation and correlates of protection: A focus on vaccines. Expert Rev. Vaccines 15, 967-976 (2016). doi:10.1586/14760584.2016.1164046 Medline

24. P. Wang, M. Wang, J. Yu, G. Cerutti, M. S. Nair, Y. Huang, P. D. Kwong, L. Shapiro, 
D. D. Ho, Increased Resistance of SARS-CoV-2 Variant P.1 to Antibody Neutralization. bioRxiv, 10.1101/2021.03.01.433466 (2021).

25. A. Baum, B. O. Fulton, E. Wloga, R. Copin, K. E. Pascal, V. Russo, S. Giordano, K. Lanza, N. Negron, M. Ni, Y. Wei, G. S. Atwal, A. J. Murphy, N. Stahl, G. D. Yancopoulos, C. A. Kyratsous, Antibody cocktail to SARS-CoV-2 spike protein prevents rapid mutational escape seen with individual antibodies. Science 369 , 1014-1018 (2020). doi:10.1126/science.abd0831 Medline

26. C. Fenwick, P. Turelli, L. Perez, C. Pellaton, L. Esteves-Leuenberger, A. Farina, J. Campos, E. Lana, F. Fiscalini, C. Raclot, F. Pojer, K. Lau, D. Demurtas, M. Descatoire, V. S. Joo, M. Foglierini, A. Noto, R. Abdelnabi, C. S. Foo, L. Vangeel, J. Neyts, W. Du, B.-J. Bosch, G. Veldman, P. Leyssen, V. Thiel, R. Le Grand, Y. Lévy, D. Trono, G. Pantaleo, A highly potent antibody effective against SARS-CoV-2 variants of concern. in review. Cell Rep. (2021). doi:10.2139/ssrn.3844718

27. N. Le Bert, A. T. Tan, K. Kunasegaran, C. Y. L. Tham, M. Hafezi, A. Chia, M. H. Y. Chng, M. Lin, N. Tan, M. Linster, W. N. Chia, M. I. Chen, L. F. Wang, E. E. Ooi, S. Kalimuddin, P. A. Tambyah, J. G. Low, Y. J. Tan, A. Bertoletti, SARS-CoV-2-specific T cell immunity in cases of COVID-19 and SARS, and uninfected controls. Nature 584, 457-462 (2020). doi:10.1038/s41586-020-2550-z Medline

28. S. A. Plotkin, Correlates of protection induced by vaccination. Clin. Vaccine Immunol. 17, 1055-1065 (2010). doi:10.1128/CVI.00131-10 Medline

29. Q. Li, J. Wu, J. Nie, L. Zhang, H. Hao, S. Liu, C. Zhao, Q. Zhang, H. Liu, L. Nie, H. Qin, M. Wang, Q. Lu, X. Li, Q. Sun, J. Liu, L. Zhang, X. Li, W. Huang, Y. Wang, The Impact of Mutations in SARS-CoV-2 Spike on Viral Infectivity and Antigenicity. Cell 182, 1284-1294.e9 (2020). doi:10.1016/j.cell.2020.07.012 Medline

30. Z. Liu, L. A. VanBlargan, L. M. Bloyet, P. W. Rothlauf, R. E. Chen, S. Stumpf, H. Zhao, J. M. Errico, E. S. Theel, M. J. Liebeskind, B. Alford, W. J. Buchser, A. H. Ellebedy, D. H. Fremont, M. S. Diamond, S. P. J. Whelan, Identification of SARS-CoV-2 spike mutations that attenuate monoclonal and serum antibody neutralization. Cell Host Microbe 29, 477-488.e4 (2021). doi:10.1016/i.chom.2021.01.014 Medline

31. R. C. H. Brown, D. Kelly, D. Wilkinson, J. Savulescu, The scientific and ethical feasibility of immunity passports. Lancet Infect. Dis. 21, e58-e63 (2021). doi:10.1016/S1473-3099(20)30766-0 Medline

32. A. H. Mohammed, A. Blebil, J. Dujaili, B. A. Rasool-Hassan, The Risk and Impact of COVID-19 Pandemic on Immunosuppressed Patients: Cancer, HIV, and Solid Organ Transplant Recipients. AIDS Rev. 22, 151-157 (2020). doi:10.24875/AIDSRev.20000052 Medline

33. P. Chen, A. Nirula, B. Heller, R. L. Gottlieb, J. Boscia, J. Morris, G. Huhn, J. Cardona, B. Mocherla, V. Stosor, I. Shawa, A. C. Adams, J. Van Naarden, K. L. Custer, L. Shen, M. Durante, G. Oakley, A. E. Schade, J. Sabo, D. R. Patel, P. Klekotka, D. M. Skovronsky; BLAZE-1 Investigators, SARS-CoV-2 Neutralizing Antibody LYCoV555 in Outpatients with Covid-19. N. Engl. J. Med. 384, 229-237 (2021). doi:10.1056/NEJMoa2029849 Medline

34. D. M. Weinreich, S. Sivapalasingam, T. Norton, S. Ali, H. Gao, R. Bhore, B. J. Musser, Y. Soo, D. Rofail, J. Im, C. Perry, C. Pan, R. Hosain, A. Mahmood, J. D. Davis, K. C. Turner, A. T. Hooper, J. D. Hamilton, A. Baum, C. A. Kyratsous, Y. Kim, A. Cook, W. Kampman, A. Kohli, Y. Sachdeva, X. Graber, B. Kowal, T. DiCioccio, N. Stahl, L. Lipsich, N. Braunstein, G. Herman, G. D. Yancopoulos; Trial Investigators, REGN-COV2, a Neutralizing Antibody Cocktail, in Outpatients with Covid-19. N. Engl. J. Med. 384, 238-251 (2021). doi:10.1056/NEJMoa2035002 Medline

Acknowledgments: We thank the Service of Immunology and Allergy at the Lausanne University Hospital for their contributions in analyzing serum samples for concentrations of anti-spike protein IgG and IgA antibodies, Madeleine Suffiotti for assistance with the statistical analysis, Laurence Durrer and Soraya Quinche from the Protein Production and Structure Core Facility at EPFL for mammalian cell culture, Michaël François from the Protein Production and Structure Core Facility at EPFL for helping in purification of the spike protein trimer proteins and ACE2-Fc protein. We would like to thank the Trono laboratory for support in performing live virus CPE assays and spike protein cloning, Caroline Tapparel for the help starting SARS-CoV-2-related work, and Isabella Eckerle for providing a SARS-CoV-2 isolate. Funding: G.P. received a grant from the Corona Accelerated R\&D in Europe (CARE) project funded by the Innovative Medicines Initiative 2 Joint Undertaking (JU) under grant agreement No 101005077. The JU receives support from the European Union's Horizon 2020 research and innovation program, the European Federation of Pharmaceutical Industries Associations (EFPIA), the Bill \& Melinda Gates
Foundation, Global Health Drug Discovery Institute and the University of Dundee. The content of this publication only reflects the author's view and the $\mathrm{JU}$ is not responsible for any use that may be made of the information it contains. Funding was also provided by the local health authorities of Cantons of Vaud (to V.D'A.) and Zurich and Basel (to M.P.), the Swiss Federal Office of Health (to M.P., J.F., S.G.N. and V.D'A.), the Lausanne University Hospital (to G.P.), the Swiss Vaccine Research Institute (to G.P.), Swiss National Science Foundation Grants (to G.P.) and through the EPFL COVID fund (to D.T.). Author contributions: P.T. established and performed the live SARS-CoV-2 virus cytopathic effect neutralization assays, designed the spike protein mutations and cloning, analyzed the results and contributed to the editing of the manuscript. C.F. conceived of and designed the spike protein-ACE2 surrogate neutralization assays, organized the testing of sera, analyzed the data, wrote the initial draft and contributed to the editing of the manuscript. C.P. optimized the conditions for the spike protein-ACE2 surrogate neutralization assays, developed the diagnostic assay, and tested all the serum samples with this assay. P.T. and C.F. designed the multiplex assay. A.F. prepared all batches of protein-coupled Luminex beads. J.C. performed all pseudoviral assays. C.R. performed sitedirected mutagenesis of the spike protein constructs. F.P. and the Protein Production and Structure Core Facility at the EPFL produced and purified the trimer spike proteins. V.C. provided initial stocks of titrated SARS-CoV-2 virus. S.G.N. and V.D'A. from the SerocoViD study and J.F. and M.P. from the Coronas Immunitas Swiss population-based study provided serum samples and information regarding the patient cohorts. D.T. and G.P. conceived the study design for sera testing, analyzed the results, and wrote the manuscript. Competing interests: C.F., P.T., G.P., and D.T are co-inventors on a patent application titled, "Cell-free method for the quantitative measurement of virus neutralizing antibodies" with filing number EP20205298.1 that covers the $S^{3}$ ACE2 multiplex assay described in this manuscript. V.D'A. sits on the Scientific Advisory Boards of the Fondation Mérieux, the Foundation for Innovative New Diagnostics (FIND), and the COVID-19 strategic board for testing, contact tracing, and clusters management with the Canton de Vaud Direction générale de la Santé. S.G.N. is the co-founder and chief medical officer of Genknowme S.A. All other authors declare no competing interests. Data availability: All data associated with this study are presented in the paper or the Supplementary Materials. Constructs and proteins listed in this manuscript can be shared by contacting the corresponding authors and completion of a material transfer agreement. This work is licensed under a Creative Commons Attribution 4.0 International (CC BY 4.0) license, which permits unrestricted use, distribution, and reproduction in any medium, provided the original work is properly cited. To view a copy of this license, visit https://creativecommons.org/licenses/by/4.0/. This license does not apply to figures/photos/artwork or other content included in the article that is credited to a third party; obtain authorization from the rights holder before using this material.

Submitted 5 April 2021

Accepted 7 July 2021

Published First Release 13 July 2021

10.1126/scitrans/med.abi8452 
A

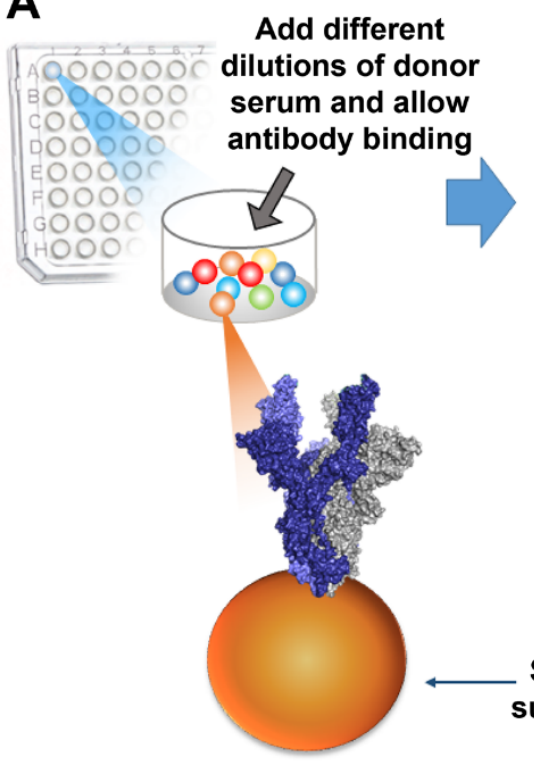

Add different dilutions of donor

B

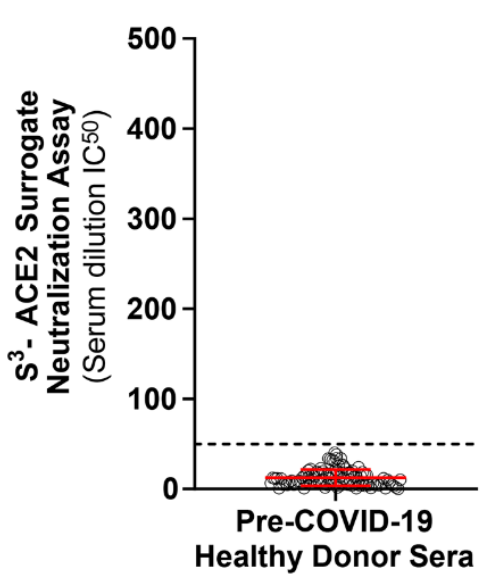

Solid support
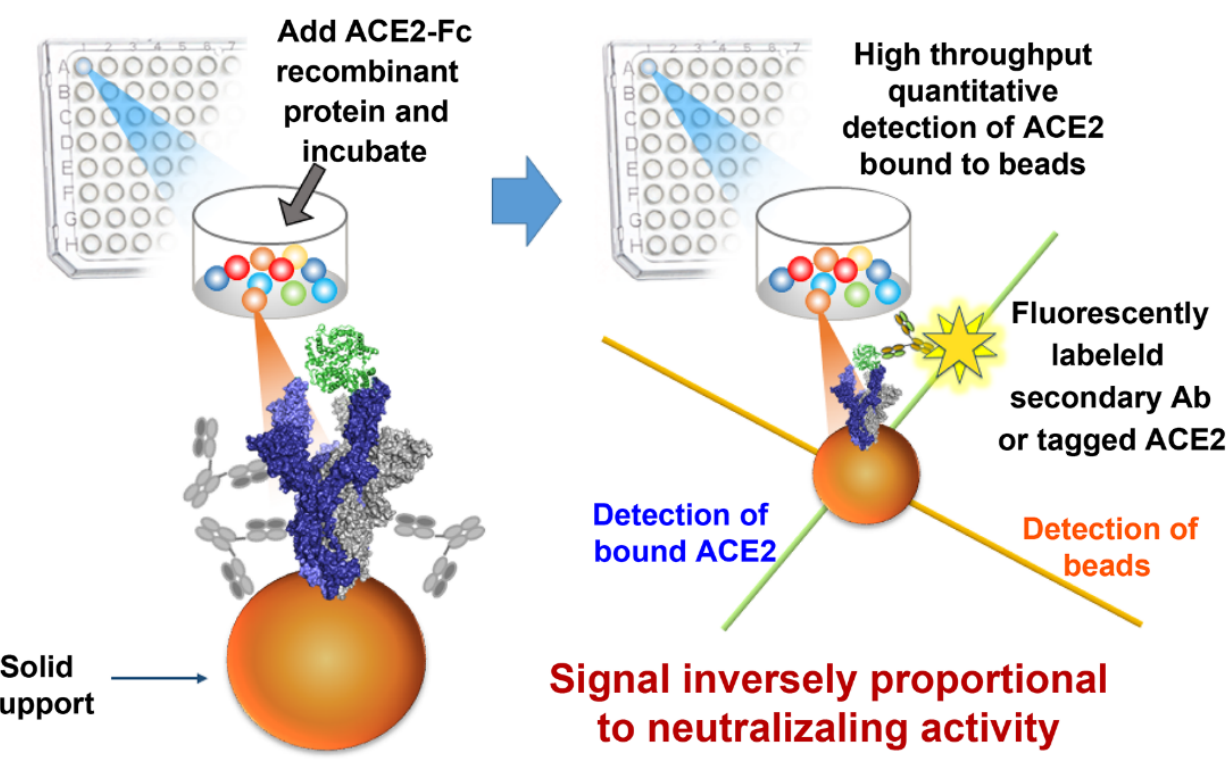

Detection of bound ACE2

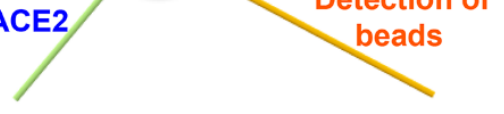

\section{Signal inversely proportional to neutralizaling activity}

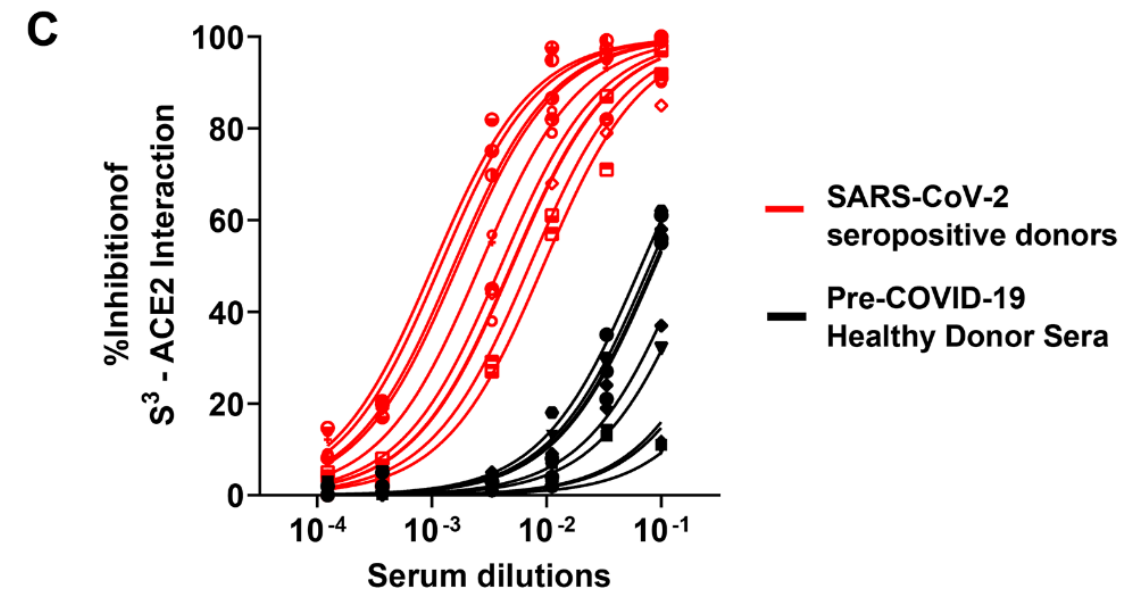

Fig. 1. Outline and validation of a cell-free SARS-CoV-2 spike protein trimer-ACE2 surrogate neutralization assay. (A) A schematic outline of the $S^{3}$-ACE2 neutralization assay is shown. Anti-SARSCoV-2 serum antibodies are monitored for their capacity in blocking the $\mathrm{S}^{3}$-ACE2 interaction. ACE2 binding to spike protein was detected though use of a fluorescently labeled secondary antibody and the signal intensities are inversely proportional to the neutralizing potential of the anti-spike protein antibodies. (B) Serum dilution $\mathrm{IC}_{50}$ values were calculated for 104 healthy adult donor samples collected prior to November 2019 (pre-COVID-19 pandemic). The mean IC 50 values and SD were used to establish a lower limit cutoff of 50 indicated by the dashed line. (C) Representative concentration response curves for ten healthy donor serum samples and ten SARS-CoV-2 seropositive donors with varying abundance of anti-spike protein IgG antibody are shown with black and red curves, respectively. Mean \pm SD are shown in (B). The spike protein and ACE2 structure was generated with PDB 7a98. 
Fig. 2. Anti-spike protein IgG and $\lg A$ concentrations in the seropositive donor groups. Anti-spike protein $\lg G(A)$ and $\lg A(B)$ antibody abundance were measured in serum samples of different donor groups using a Luminex Spike trimer serological assay. Donors were considered seropositive for anti-spike protein IgG or $\lg A$ antibodies with positivity cutoffs (red dashed lines) of 4 and 6.5 ratios over a standard negative control, respectively. Boxplots shown mean and the 95\% interquartile range.
A

anti-spike protein IgG abundances

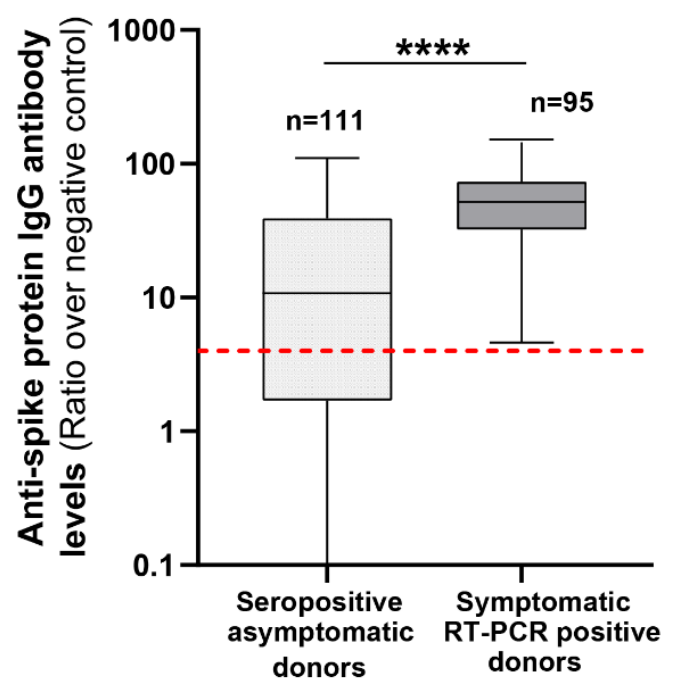

B

anti-spike protein $\lg \mathrm{A}$ abundances

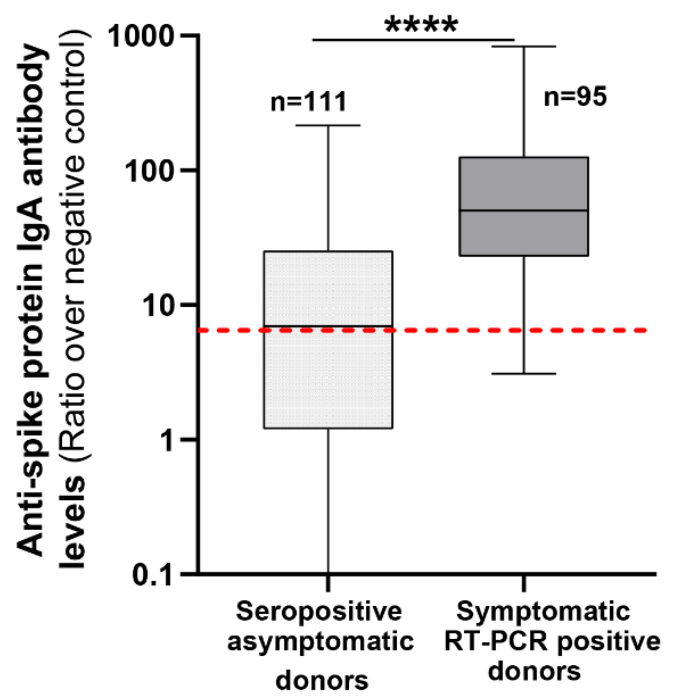


Fig. 3. Cross-validation of a cellfree SARS-CoV-2 spike protein trimer-ACE2 surrogate neutralization assay. (A) The results of a cross-validation study between $S^{3}$-ACE2 surrogate neutralization assay and a SARS-CoV-2 CPE neutralization assay are shown. Seropositive donors $(n=206)$ with varying anti-spike protein antibodies were selected for comparison of the assays. Donors consisted of patients hospitalized with COVID-19 ( $n=31$, red dots), RT-PCR positive symptomatic donors ( $n=64$, orange dots) and other asymptomatic seropositive donors identified through random sampling, volunteers, or as contact with a confirmed SARS-CoV-2 infected individual in a serological survey ( $n=111$, light blue dots). The correlation between the two neutralization assays is represented by the black dashed line, the 50 serum dilution $\mathrm{IC}_{50}$ cutoff for positivity in the $S^{3}$-ACE2 surrogate neutralization assay is shown with a crimson dashed line and the 20 serum dilution $\mathrm{IC}_{50}$ cutoff for positivity in the CPE assay is shown with the blue dashed line. (B) The correlation between a live SARSCoV-2 virus CPE assay and spike protein pseudotyped neutralization assays are shown. A group of 74 samples from seropositive donors were compared in the live virus CPE and spike protein pseudotyped virus cell based neutralization assays. The dots are colored as in (A). The correlation between the two neutralization assays is represented by the black dashed line and the 20 serum dilution $\mathrm{IC}_{50}$ cutoff for positivity in the CPE assay is shown with the blue dashed line.
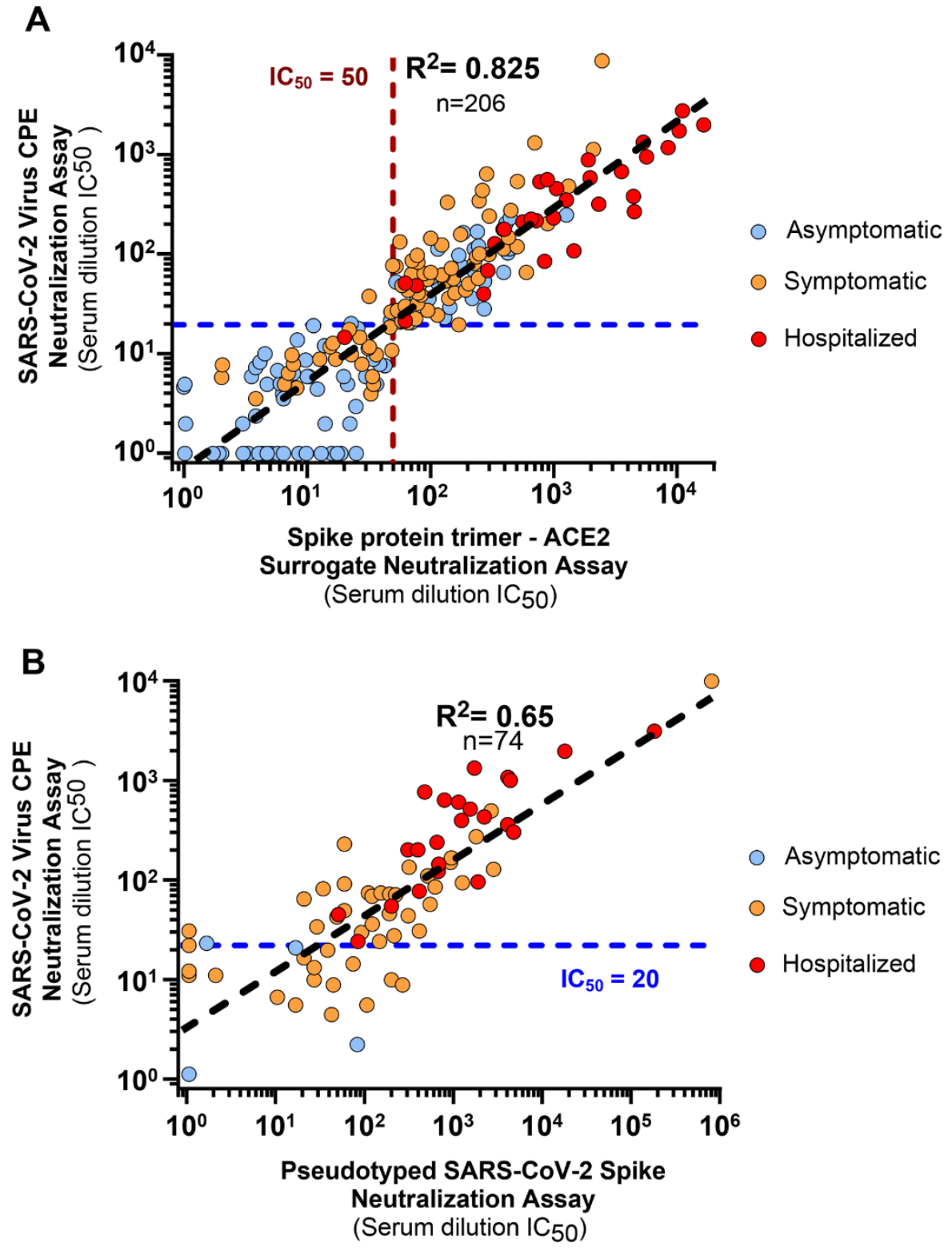

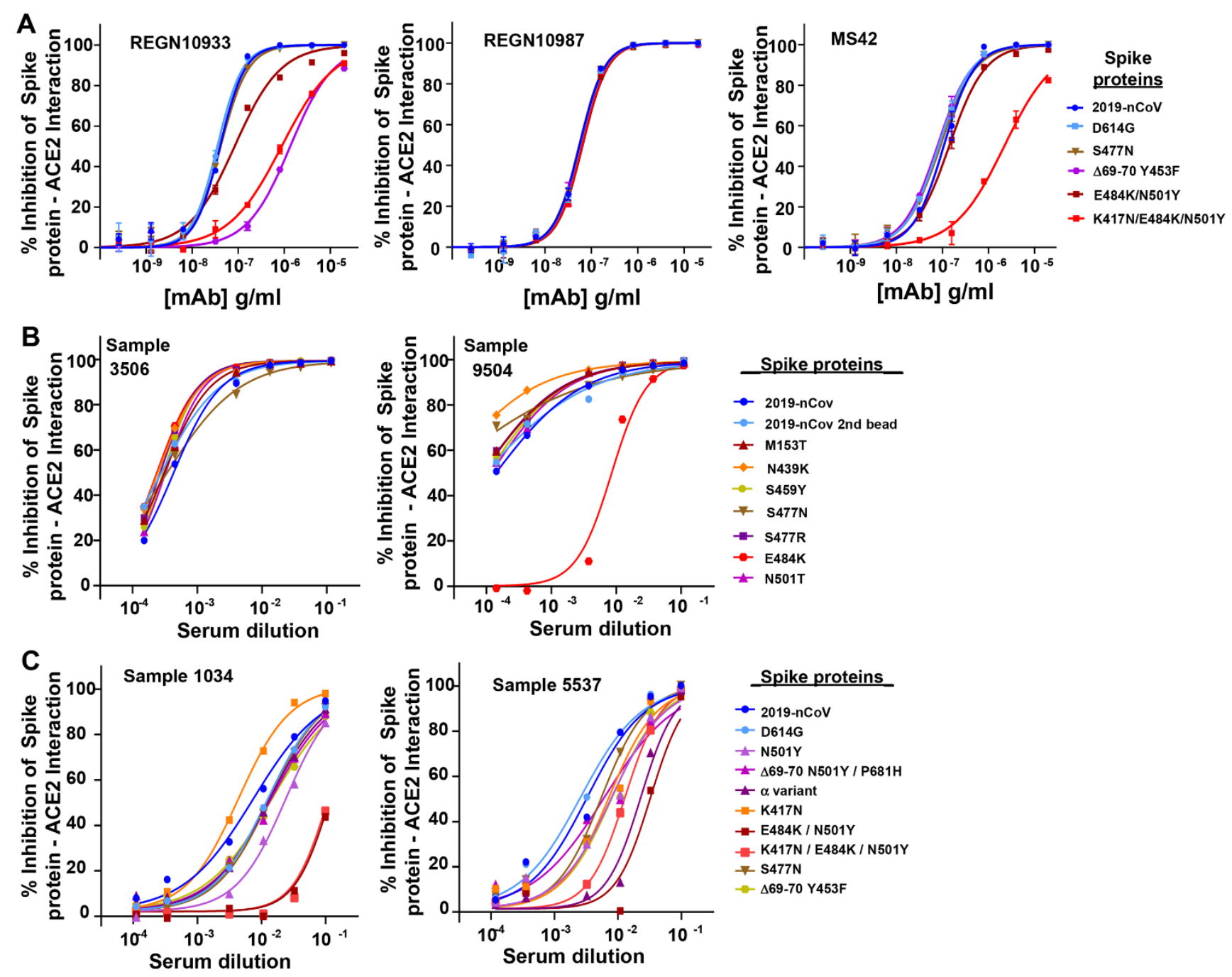

D

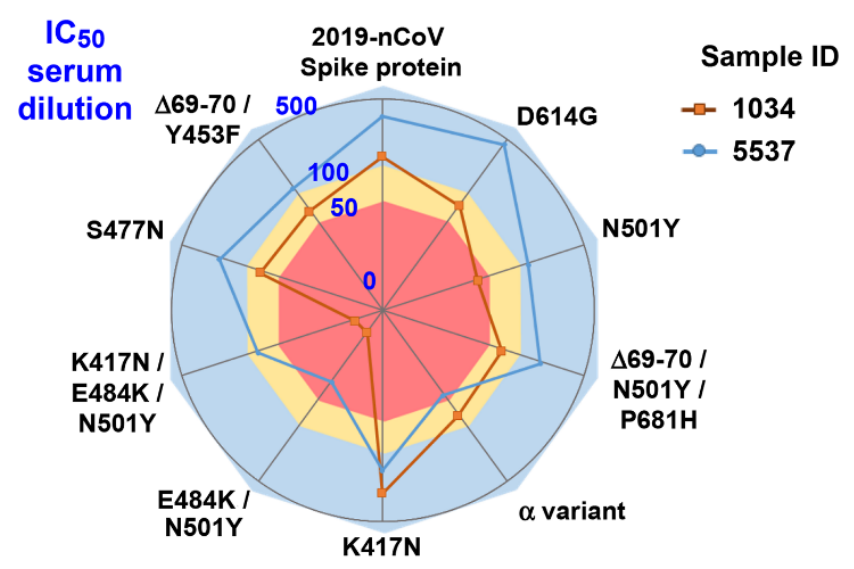

Spike proteins used in Surrogate Neutralization Assay (IC50 serum dilution)

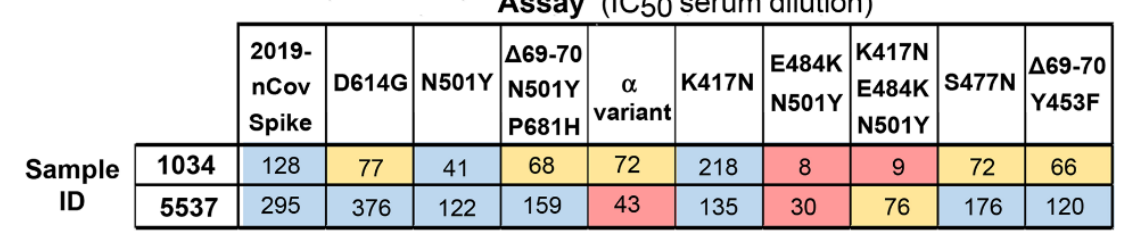


Fig. 4. Multiplexed analysis of antibody and serum neutralizing activity against VOC spike protein mutations. The surrogate neutralization assay was performed with two panels of $S^{3}$-coupled beads consisting of the 2019-nCov spike protein and spike mutations produced with one or more amino acid substitutions or deletions. (A) Concentration response curves of the REGN10933, REGN10987 and MS42 monoclonal antibodies were evaluated against spike protein and mutations from five viral variants in the $\mathrm{S}^{3}$-ACE2 assay. (B and C) Serum dilutions from RT-PCR positive donors 3506 and 9504 (B) or 1034 and 5537 (C) were tested with two separate panels of S $^{3}$-coupled beads. (D) A spider plot and heatmap show $\mathrm{IC}_{50}$ serum dilutions for donors 1034 and 5537 serums samples against the indicated spike protein mutations found in variants of concern including $\alpha$ and $\beta$. Blue corresponds to an $\mathrm{IC}_{50}$ dilution greater than 100 , yellow corresponds to $\mathrm{IC}_{50}$ dilutions from 50 to 100 , and red corresponds to $\mathrm{IC}_{50}$ dilutions below 50 . 


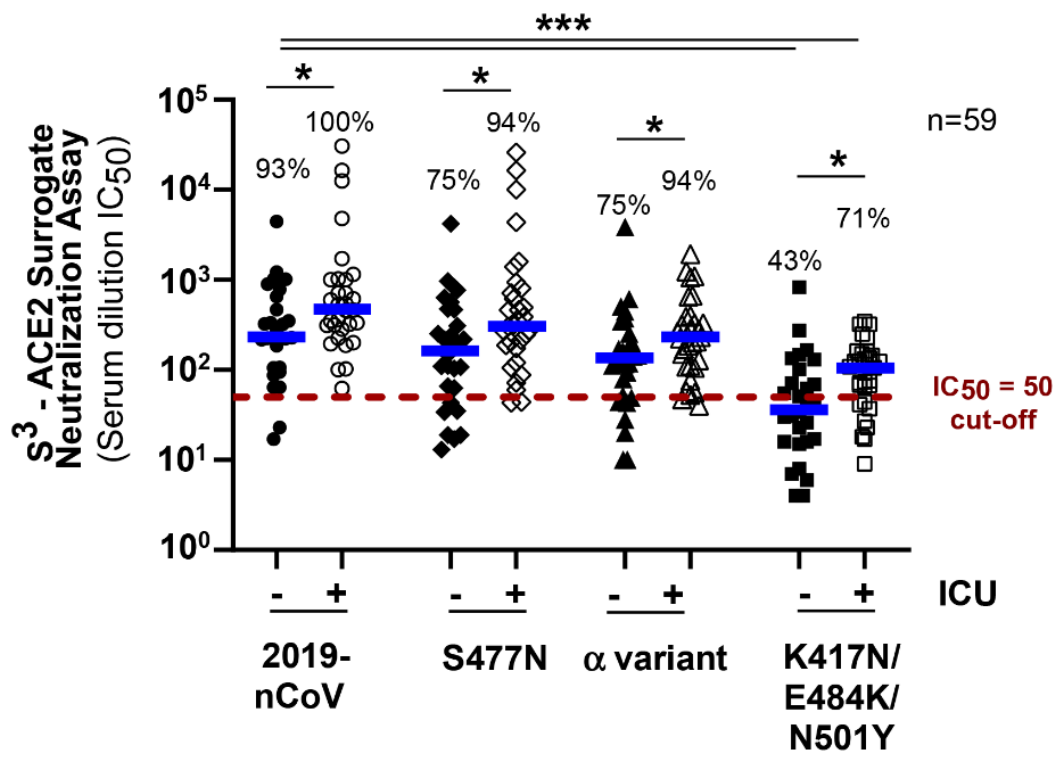

Fig. 5. Multiplexed analysis of COVID-19 patient serum samples reveals differences in neutralizing activity against spike protein mutations associated with VOCs. Serum samples from 59 patients hospitalized with COVID-19 were profiled in the multiplexed S ${ }^{3}$-ACE2 surrogate neutralization assay performed in parallel with the 2019-nCov spike protein and three spike mutants produced with one or more amino acid substitutions or deletions. $S^{3}$-ACE2 serum dilution $I C_{50}$ values for each of the spike proteins were calculated for samples from the 28 non-ICU donors (closed symbols) and for 31 COVID-19 patients that required ICU care (open symbols). The dashed crimson line indicates the $\mathrm{IC}_{50}$ value cut-off of 50 that corresponds to neutralizing antibody abundance needed for near complete neutralization in the live virus CPE assay. Percentages of serum samples above this cut-off are shown for non-ICU and ICU donors for each of the spike proteins tested. Median values are shown as blue bars. Statistical analysis was performed using a two-way ANOVA test for patient and spike protein mutant groups comparisons where $\mathrm{P} \leq 0.091$ $\left({ }^{*}\right) ; P \leq 0.0008\left({ }^{* * *}\right)$. 
Table 1. The performance of the cell-free $S^{3}$-ACE2 surrogate neutralization assay was benchmarked against a SARS-CoV-2 live virus CPE neutralization assay. TP: true positives, FN: false negatives, TN: true negatives. Neutralizing activity in the live virus CPE assay

\begin{tabular}{lccc} 
& & + & - \\
\hline & + & True $+(\mathbf{T P})$ & False $+(\mathbf{F N})$ \\
$\mathbf{S}^{3}$-ACE2 & & $\mathrm{n}=118$ & $\mathrm{n}=0$ \\
assay & - & False $-(\mathbf{F N})$ & True $-(\mathbf{T N})$ \\
& & $\mathrm{n}=4$ & $\mathrm{n}=84$ \\
& Sensitivity & Specificity \\
& & $\mathbf{T P} / \mathbf{T P}+\mathbf{F N})$ & $=\mathbf{T N} /(\mathbf{F P}+\mathbf{T N})$ \\
& $=96.7 \%$ & $=\mathbf{1 0 0} \%$ \\
\hline
\end{tabular}

Table 2. Spike protein mutations in different circulating SARS-CoV-2 variants of concern

SARS-CoV-2 Spike Protein Mutations

Variant

\begin{tabular}{ll}
\hline$\alpha /$ B.1.1.7 & $\triangle 69-70, \triangle 144$, N501Y, A570D, D614G, P681H, T716I, S982A, D1118H \\
$\beta /$ B.1.351 & L18F, D80A, D215G, $\triangle 242-244$, R246I, K417N, E484K, N501Y, D614G, \\
& A701V \\
$\gamma /$ P.1 & L18F, T20N, P26S, D138Y, R190S, K417T, E484K, N501Y, D614G, H655Y, \\
& T1027I, V1176F \\
\hline
\end{tabular}

